\title{
An Analysis of the Impact of Hindi Language on the Language Use of Young Pakistani
} Females

\author{
Amna Fajar \\ M. Phil Scholar, University of Lahore, Lahore \\ Dr. Sikander Ali \\ Associate Professor, The University of Lahore, Lahore
}

\begin{abstract}
This study investigates the Hindi language impact on Pakistani young females' language. The young generation of a country is considered as a strong pillar for national development. The purpose of this study is to analyze the major effects of watching Indian dramas on the language of Pakistan's young females. For this study, the researcher has selected two colleges and used the qualitative method that involves close-ended questions. In the sampling process, the non-probability sampling technique has been used which includes judgmental sampling. For the study, 70 samples from the target population have been collected. The study records students' normal T.V watching hours, their preference for using the Hindi language words in their daily routine, and the place of their acknowledgment about these words. The results show that efforts of Indian media for cultivating their culture in Pakistan is somehow getting successful and in that purpose the greed of cable operators and negligence of PEMRA is at the peak. Students have taken the phenomena of using Hindi language into their daily routine as normal one without realizing that the utilization of the Hindi language is adversely impacting their native language (Urdu) and again taking them back towards the period/era of colonization.
\end{abstract}

Keywords: Young Females, Impact of Hindi Dramas, Pakistani language.

\section{Introduction}

A language is a systematic and structured way of communication; it enables people to communicate with each other. "Every community has its own set of languages, it is an obvious factor that when two languages have contact with each other, they influence or impact each other" (Bloomfield, p. 12).

\subsection{Background of the Study}

"Digital and broadcast media plays a vital role in our everyday lives and people are so much habitual of its usage that one is lost without any of these networks" (Hayes, p. 5).In this modern age, Private Media takes a very important part in Pakistani community. Considerations about the influence / impacts of media always intensify when a new communication technology is implemented in society, because technology always has some positive or negative implications. Pakistani society is in a perilous zone. Cable TV viewing is no longer limited to any class. It is cheap in price and easy to access, that is the main reason of the high amount of its viewership. Pakistani children are more conscious of Hindu culture and Hindi language than their own language and culture because of their excess exposure 
towards Indian media; children blend Hindi words in Urdu and use them in their daily routine conversations. Indian dramas have a damaging influence on Pakistani media, language, culture and general public in Pakistan. Crucial fact is that the influence of Indian dramas is so high, no matter how far we advance, it will take a long time to take off its negative impact.

Pakistan is a Muslim country but sadly due to the cult of modernization and westernization, people have adopted Western and Indian culture. Indian dramas have a significantly adverse impact on our language as Pakistani people spend much of their time watching Indian television as compared to local (Pakistani) channels. They like to watch Star plus, Sony TV, Zee TV etc. Females overlook their household chores and spend time watching star plus dramas. People talk about these dramas at their dining tables, throughout travel and even at their workplace.

\subsection{Statement of the Problem}

This study highlights the actual reason or motive of Pakistani females to use/ incorporate Hindi language as their source of communication in their personal or professional life. The purpose is to give the description of reasons about Pakistani peoples 'selection of Hindi words rather than using their own Pakistani (native) cultural or language words.

\subsection{Aims and Objectives}

1. To investigate the effect of Indian dramas on the viewer's native language.

2. To find out which channels lead to the learning of Hindi language that is adopted by Pakistani young females.

3. To analysis, the young Pakistani female's phenomena of the use of Hindi dialogues /wordsin their daily lives.

\subsection{Research Questions}

The questions for this research purpose are

- How the Indian dramas are affecting one's first/ native language?

- Which channel leads to the learning process of the Hindi language?

- How the young Pakistani females taken the phenomena of the use of Hindi dialogues in their daily lives?

\subsection{Significance of the Study}

This study is important and helpful in understanding the impact of Indian dramas on the verbal communication process and social interaction in Pakistani society. Today, the young generation is more concerned and focused on using Hindi words and forgetting the roots of their own cultural (native / Pakistani) language. This study highlights the factors that have the solid impact on the Hindi language use especially by females in their professional or personal life.

\subsection{Delimitation of the Study}

The collection of data from all the females of Pakistan is delimited because of the large number of population; one is not able to reach to all the female population of the 
country that is why data is collected from limited population of two colleges of Lahore city. Ethics for the collection of data are kept in mind.

\section{$2 \quad$ Literature Review}

Electronic media is a powerful source of spreading any information, norms, culture or traditions. People update themselves with social events through electronic media. In the $21^{\text {st }}$ century, "language, culture and media are a part of society. Cultural difference is considered as the main issue of inter-cultural communication" (Ashfaq, 2028:5) Media serve to represent things depend on the demand. Media is free and acts as a guard because it influences the people thoughts, language and lifestyle. In media, dramas are important as they are a source of entertainment it indicates a culture, its beauty, its language and uniqueness that attracts people towards it.

\subsection{Dramas and their Impact on People}

Creating a drama is an art that involves multiple people effort and a story. Since many years' dramas are a part of human life especially for women, whenever they get free time they switch on the T.V and watch their favorite serial."This source of entertainment attracts viewers and relaxes them after their daily life's hectic routine" (Yousaf, 2014).Many countries around the world produce dramas like America, South Korea, Iran, Turkey, Australia, Indonesia, India, Japan, China and last but not least Pakistan. Dramas not only act as a source of entertainment, but also help to promote the country's culture. India has been producing dramas for decades. The very first Indian drama was telecasted in 1985. A study on the effects of dish antenna expresses that; in a Pakistani society, dish antennas are the source of shaping socio-cultural values and language effects. This study highlighted that due to the high amount of on-air Hindi dramas people are taking Islamic culture as conservative one (Hassan, Khalid, \& Ali, 2015, p. 3). "Zia (2003) considered it as the major reason for cable grow with feasible access, low in cost, exposure to satellite channels and a source of entertainment for television viewers"(Mahmood, 2018). Shafiq implies that "the number of private satellite channels increased, but for the public, PTV did not create any new and interesting programmers. The quality of the programs had declined. Citizens wanted to watch Zee TV with the advent of the dish antenna and loved BBC. No at the same time there are ten channels in the Urdu language in comparison with PTV" (Shah \& Aziz, 2017, p. 6).

As time passes, social life is changing because of the online media networks, now people want to discuss various dramas at mealtime. This change in our society is mainly due to massive exposure of the Indian media. The impact of Indian TV shows seems to be slowly nipping at the heels of the Pakistan national language (Urdu). Even the way one speak, has changed. "Sonia Gandhi once said in an interview that India has won the cultural war against Pakistan since the Pakistani youth may not know the names of their great historic personalities but they surely know the names of famous Indian actors" (Batool, 2017).Different rituals and customs celebrated in Pakistan are not part of the Pakistani / Islamic culture, but because of the popularity of Indian media in Pakistan, these customs have become part of Pakistani culture and replaced Pakistani local rituals, customs and traditions. 
Today, "people watch Indian programs and many Hindi words are being adopted by the people in the society. In everyday communication, they use Hindi words, e.g. "Didi (sister)", "jeeja (brother in law)", "shanty (sakoon)", "Vishwas (trust)", Namaste (hello)", "Praja (people)","sapna(dream)" etc. In Pakistan, variety of programs on television is broadcasted through cable and satellite channels" (Majeed, 2018). The cable operators mostly prefer to show English films and cartoons dubbed in Hindi language, which is one of the main reasons for its influence in the common Pakistani's language."The dubbing of Hollywood movies in the Hindi language is also the reason for the increasingly high amount of viewers and people are adopting Hindi language" (Juni, 2014, p. 2).

\subsection{Theory of Cultivation}

The theory of cultivation is basically a socio-cultural theory which argues that the behaviors of a viewer are mainly shaped by what they watch on television. In its most simplistic form, "Cultivation Theory argues that television is responsible for influencing or 'cultivating' viewers' views of social reality. The collective influence of large television viewers' exposure over time gradually influences people and their understanding of social reality. The more people watch T.V; regarding anything, the more they adopt that thing in their practical life" (Shrum, 2017, p. 3).

\section{Research Methodology}

In this study, the research methodology uses to find the results of the study with the help of representatives of data collection of the participants and its procedure of analysis. This study includes a quantitative method that consists of close-ended questions. The target population for data collection is young Pakistani females because more than men, females prefer to watch television. "Researchers believe that the social difference between male and female create that discrimination in their communication as females are supposed to talk more to maintain a balance in the relationship than boys. Males prefer to watch the news whereas females prefer to watch television that is far away from reality and less the fatigue of their daily routine work" (Bailey, 2014).

The non- probability sampling technique which includes judgmental sampling is used for this study. The purpose of selecting this sampling (judgmental sampling) technique is that the researcher is aware of the area from which data is easy to collect in a more authentic form. The target people are young females from 17-24 years old because in young age, females are less concerned about what they say, as it is considered as the carefree age whereas adult women prefer to be conscious in the selection of words (Schwartz, 2010).70 samples are collected from the population. The participants in the data collection are the female students of LCWU (Lahore College for Women University) and QMC (Queen Marry College Lahore).

\section{Data Analysis}

In this study, the questionnaire consists upon closed ended questions. The study of statistical data for each element in the questionnaire is provided in the form of tables. These 
tables display the ratios, proportions and combined ratios of the sample responses. For easy visual inspection even the bar charts of the tables are sketched.

Table no 4.1

What is your age?

\begin{tabular}{llcc}
\hline & Frequency & Percentage $(\%)$ & Cumulative percent \\
\hline $15-18$ & 61.6 & 88 & 88 \\
$19-25$ & 8.4 & 12 & 100 \\
More than 25 & 0 & 0 & \\
Total & 70 & 100 &
\end{tabular}

\section{Result}

$88 \%$ of participants are between $15-18$ year's age, $12 \%$ are between $18-25$ years, whereas $0 \%$ are the ones who are more than $25 \%$ in their age.

Table no 4.2

Q. What is the level of your education?

\begin{tabular}{llcc}
\hline & Frequency & Percentage $(\%)$ & Cumulative percentage \\
\hline Intermediate & 62.3 & 89 & 98 \\
Undergraduate & 7.7 & 11 & 100.0 \\
Post-graduate & 0 & 0 & \\
Total & 70 & 100.0 &
\end{tabular}




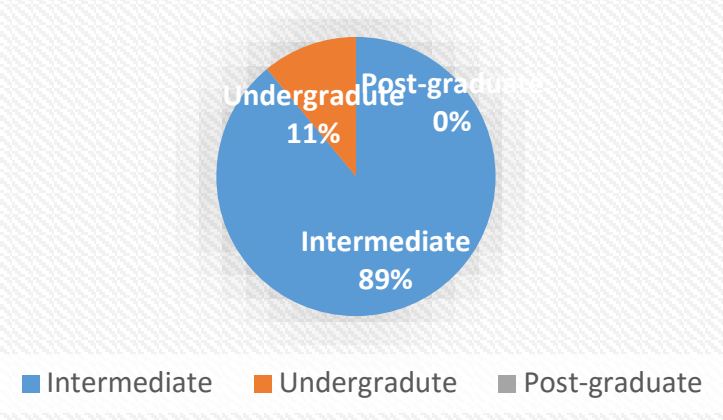

\section{Result}

$89 \%$ participants answer that they are the intermediate students, $11 \%$ participants answer that they are undergraduate students, whereas $0 \%$ are the post-graduate students.

\section{Table no 4.3}

Q: What is your second language?

\begin{tabular}{|c|c|c|c|}
\hline & Frequency & Percentage $(\%)$ & Cumulative Percentage \\
\hline Punjabi & 16.1 & 23 & 23 \\
\hline Hindi & 0 & 0 & 23 \\
\hline English & 29.4 & 42 & 65 \\
\hline Urdu & 24.5 & 35 & 100.0 \\
\hline Total & 70 & 100.0 & \\
\hline
\end{tabular}

\section{Result}

$42 \%$ of participants take English as their second language, 35\% consider the Urdu language as their second language, $23 \%$ of students take the Punjabi language as their second language whereas $0 \%$ declares Hindi as their second language.

\section{Table no 4.4}

Q: How often you watch television in spare time?

\begin{tabular}{llcc}
\hline & Frequency & Percentage $(\%)$ & Cumulative percentage \\
\hline $1-3$ hours & 14 & 20 & 20 \\
4-6 hours & 49 & 70 & 90 \\
More than 6hours & 7 & 10 & 100.0 \\
Total & 70 & 100.0 &
\end{tabular}




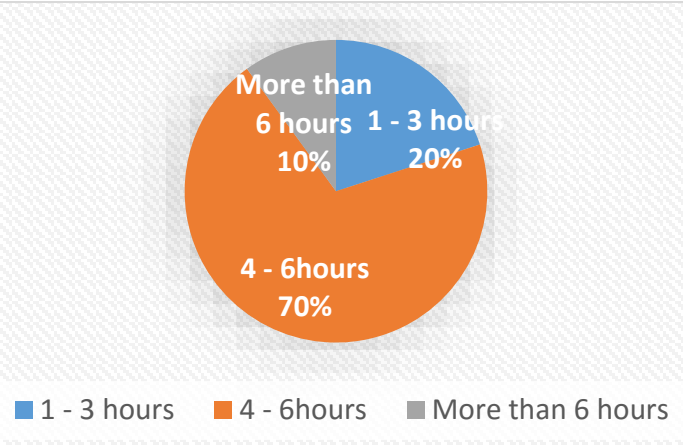

\section{Result}

$70 \%$ of participants prefer to watch television for $4-6$ hours to spend their spare time, $20 \%$ of participants prefer to watch it $1-3$ hours whereas $10 \%$ of participants prefer to watch it for more than 6 hours.

\section{Table no 4.5}

Q: What you prefer to watch in your spare time?

\begin{tabular}{|c|c|c|c|}
\hline & Frequency & Percentage (\%) & Cumulative percent \\
\hline Seasons & 5.9 & 8 & 8 \\
\hline Dramas & 59.5 & 85 & 93 \\
\hline Movies & 4.9 & 7 & 100.0 \\
\hline Total & 70 & 100.0 & \\
\hline
\end{tabular}

\section{Result}

$85 \%$ of participants prefer to watch dramas on the television, $7 \%$ students answer that they prefer to watch movies broadcasted on the television, whereas $8 \%$ of students answer that they like to watch seasons more than dramas and movies.

Table no 4.6

Q: Which industrial drama you prefer to watch in your spare time?

\begin{tabular}{llcc}
\hline & Frequency & Percentage $(\%)$ & Cumulative Percentage \\
\hline Pakistani & 29.4 & 42 & 42 \\
Indian & 40.6 & 58 & 100.0 \\
Total & 70 & 100.0 &
\end{tabular}




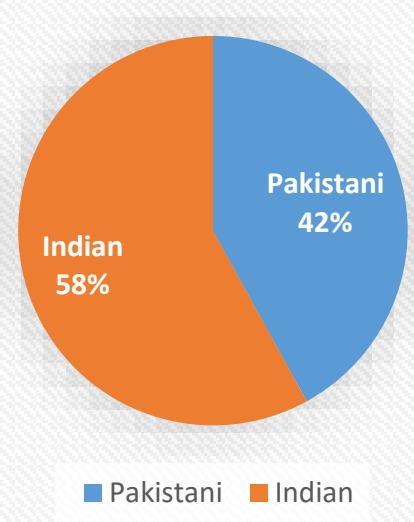

\section{Result}

$58 \%$ of students prefer to watch Indian dramas on T.V in their spare time whereas $42 \%$ of students retrieve that they prefer to watch Pakistani dramas on T.V more than Indian dramas.

\section{Table no 4.7}

Q: Do you ever use Hindi Phrase or dialogues like "Sanskar"?

\begin{tabular}{llcc}
\hline & Frequency & Percentage $(\%)$ & Cumulative Percentage \\
\hline Yes & 49 & 70 & 70 \\
No & 4.2 & 6 & 76 \\
Sometimes & 6.3 & 9 & 85 \\
Mostly & 10.5 & 15 & 100.0 \\
Total & 70 & 100.0 &
\end{tabular}

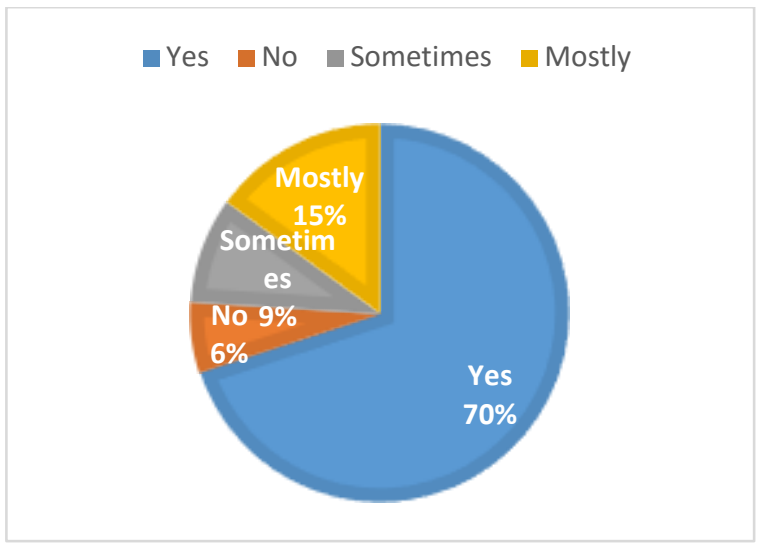

\section{Result}

$70 \%$ of participants retrieve with yes that they prefer to use the Hindi language, $15 \%$ of students say that they mostly prefer to use the Hindi proverbs in their lives, $9 \%$ of students prefer to use it sometimes whereas $6 \%$ do not prefer to utilize it in their daily lives.

\section{Table no 4.8}

Q: Do you use Hindi dialogues at your professional level? 


\begin{tabular}{llcc}
\hline & Frequency & Percentage $(\%)$ & Cumulative Percentage \\
\hline Yes & 14 & 20 & 20 \\
No & 38.5 & 55 & 75 \\
Sometimes & 11.9 & 17 & 92 \\
Mostly & 5.6 & 8 & 100.0 \\
Total & 70 & 100.0 &
\end{tabular}

\section{Result}

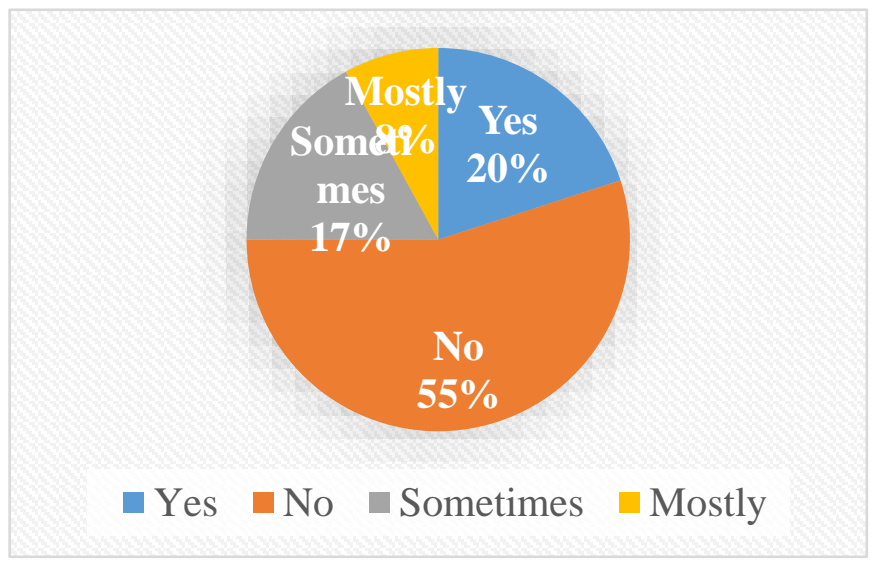

55\% participants do not prefer to use the Hindi language at their professional level, 20 $\%$ like to utilize it even at their professional level, $17 \%$ like to use it sometimes at their workplace, whereas $8 \%$ mostly depend upon the use of the Hindi language even at their professional place.

\section{Table no 4.9}

Q: With whom you prefer to speak Hindi words more?

\begin{tabular}{|c|c|c|c|}
\hline & Frequency & Percentage $(\%)$ & Cumulative percentage \\
\hline Friends & 65.8 & 94 & 94 \\
\hline Family & 2.8 & 4 & 98 \\
\hline Colleagues & 1.4 & 2 & 100.0 \\
\hline Total & 70 & 100.0 & \\
\hline
\end{tabular}

\section{Result}


94\% of participants prefer to use the Hindi language with their friends, $4 \%$ prefer to use it with their families, whereas $2 \%$ of the participants like to utilize the Hindi language with their colleagues.

Table no 4.10

Q: How do you take this phenomenon of using Hindi words in your daily life?

\begin{tabular}{llcc}
\hline & Frequency & Percentage $(\%)$ & Cumulative Percentage \\
\hline Good & 54.6 & 78 & 78 \\
Bad & 11.2 & 16 & 94 \\
Neutral & 4.2 & 6 & 100.0 \\
Total & 70 & 100.0 &
\end{tabular}

\section{Result}

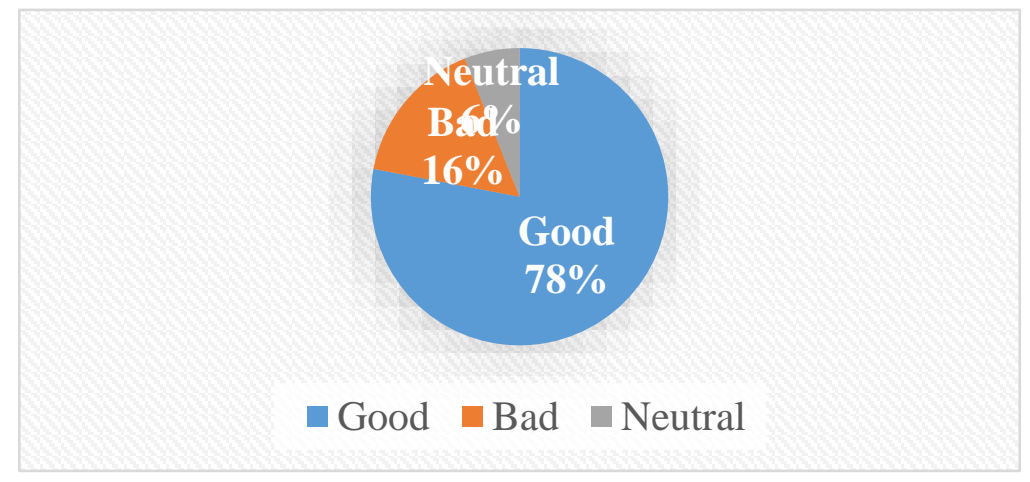

$78 \%$ of participants taking the phenomena of using the Hindi language in a good way, $16 \%$ consider that using the Hindi language is not good whereas $6 \%$ take this question as a neutral one.

\section{Table no 4.11}

Q: How the Indian dramas are affecting one's first/ native language?

\begin{tabular}{llcc}
\hline & Frequency & Percentage $(\%)$ & Cumulative Percentage \\
\hline Yes & 38.5 & 55 & 55 \\
No & 19.6 & 28 & 83 \\
Maybe & 11.9 & 17 & 100.0 \\
Total & 70 & 100.0 &
\end{tabular}

\section{Maybe}

\section{$7 \%$}

No

Yes

$31 \%$

$62 \%$

$\square$ Yes $\square$ No $\square$ Maybe 


\section{Result}

$62 \%$ of participants think that yes using the Hindi language is affecting their first language perception and usage, $31 \%$ participants disagree with this perspective that the Hindi language is not able to affect their first language, whereas $7 \%$ participants take these questions in the neutral way they support both phenomena of yes and no.

Table no 4.12

Q: From which place you get familiar with Hindi words?

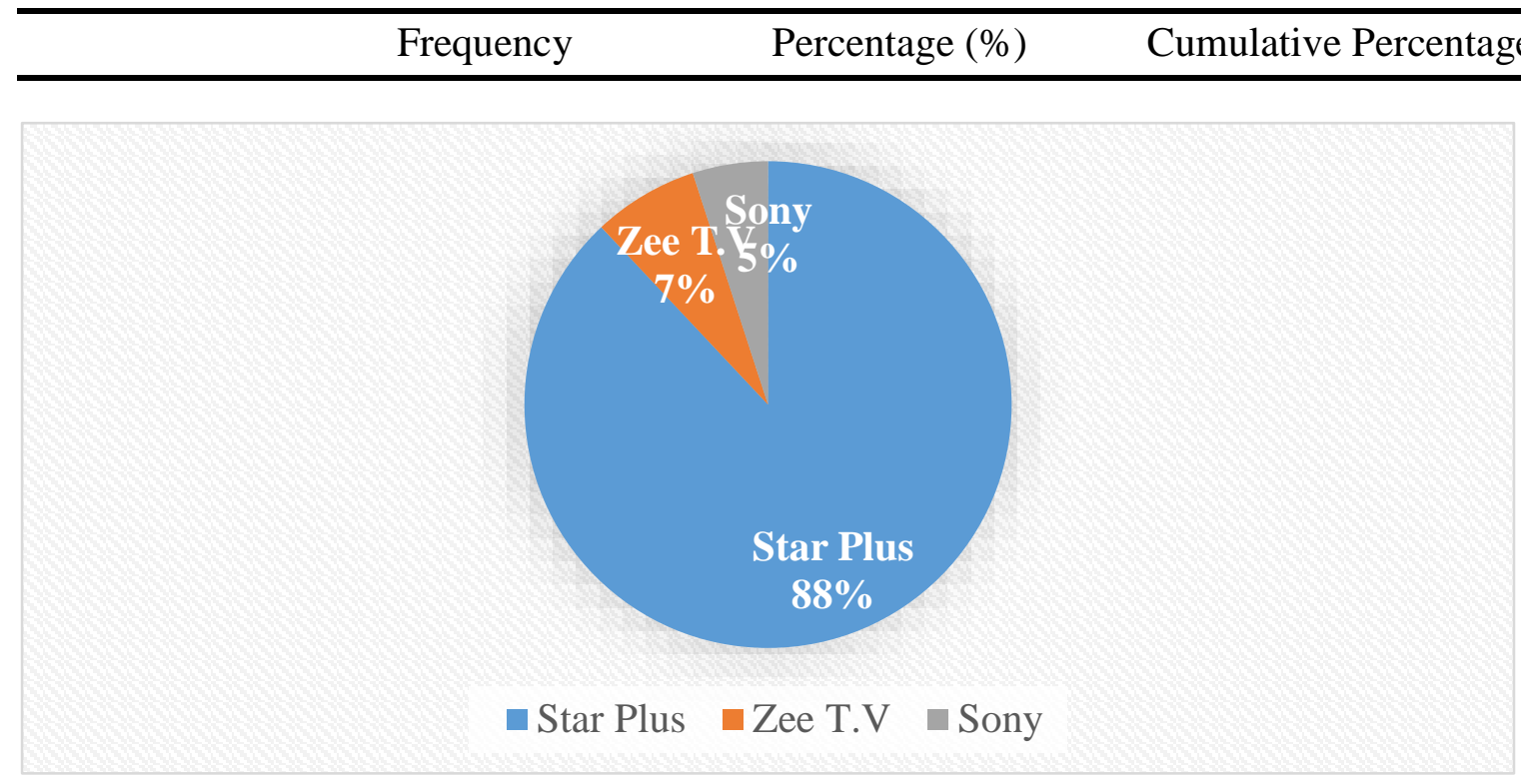

$\begin{array}{llll}\text { Dramas } & 63 & 90 & 55 \\ \text { Movies } & 7 & 10 & 100.0 \\ \text { Real life } & 0 & 0 & \\ \text { Total } & 70 & 100.0 & \end{array}$

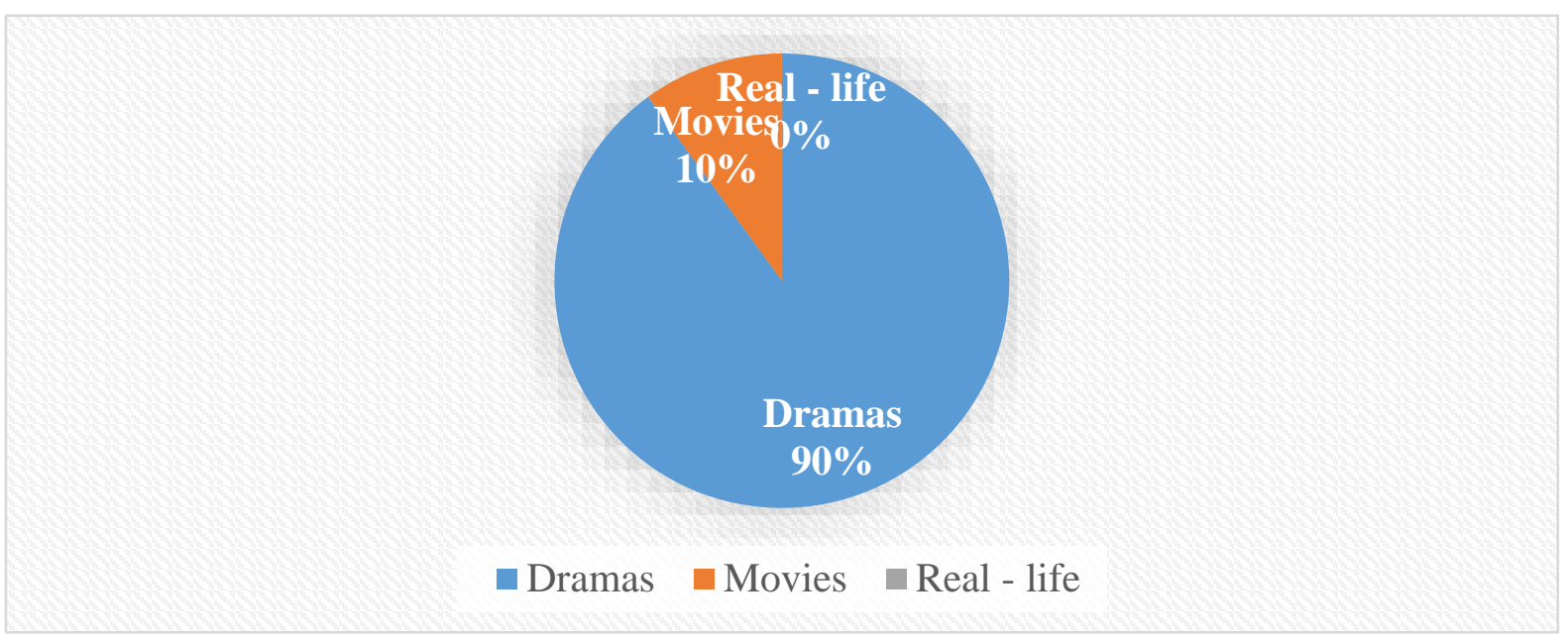




\section{Result}

90\% of participants consider that they learn Hindi language words from dramas more than any place as compare to it $10 \%$ of participants consider that they learn words from movies whereas $0 \%$ think that they learn it from real life.

Table no 4.13

Q: Which channel leads to the learning process of the Hindi language?

\begin{tabular}{llcc}
\hline & Frequency & Percentage $(\%)$ & Cumulative Percentage \\
\hline Star plus & 61.6 & 88 & 88 \\
Zee T. V & 4.9 & 7 & 95 \\
Sony & 3.5 & 5 & 100.0 \\
Total & 70 & 100.0 &
\end{tabular}

\section{Result}

$88 \%$ of participants consider that the star plus is the channel which usually the progressive one in promoting the Hindi language, $7 \%$ of participants think that the Zee T.V is the foremost channel of promoting the Hindi language whereas $5 \%$ of participants give thiscreditof promoting the Hindi language to Sony channel.

\section{Table no 4.14}

Q: How the young Pakistani females taken the phenomena of the use of Hindi dialogues in their daily lives??

\begin{tabular}{|c|c|}
\hline Good & Bad \\
\hline Because it is cool. & Because it is not our cultural language. \\
\hline $\begin{array}{l}\text { It is increasing our knowledge about } \\
\text { different languages. }\end{array}$ & It is destroying our own language concept. \\
\hline We are becoming Multilingual. & $\begin{array}{l}\text { We are dragging our language towards the } \\
\text { position of a dead language. }\end{array}$ \\
\hline
\end{tabular}

\begin{tabular}{llcc}
\hline & Frequency & Percentage $(\%)$ & Cumulative Percentage \\
\hline Good & 50.4 & 72 & 72 \\
Bad & 19.6 & 28 & 100.0 \\
Total & 70 & 100.0 &
\end{tabular}




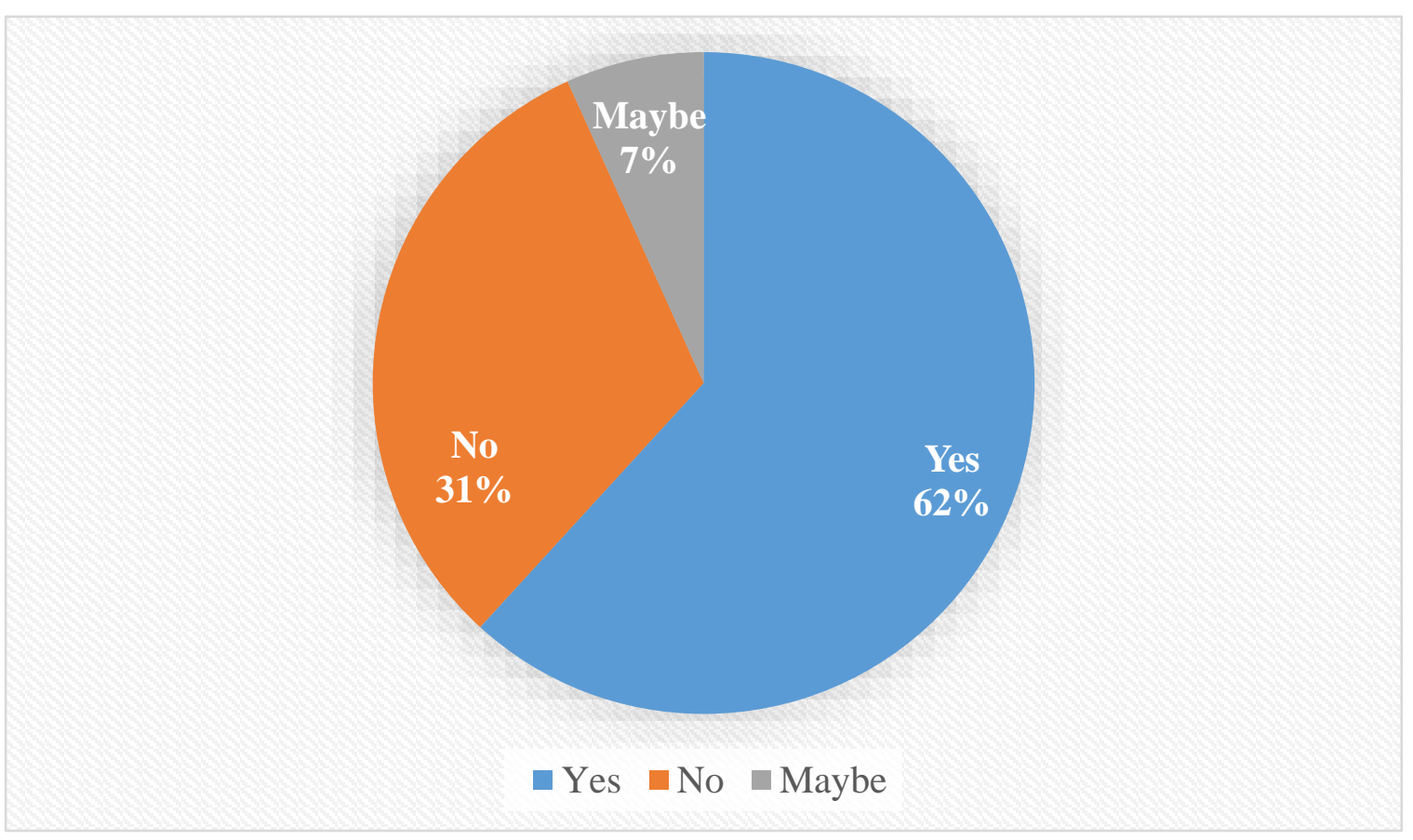

\section{Result}

$62 \%$ of participants answer that it is not bad to use any other language to communicate, some support it that the use of the Hindi language makes them feel cool that they are using a different language from the native one,31\% consider that it is not good to use the Hindi language on any perspective because the utilization of the Hindi language makes us drag our own language towards the dead one, some take it as not a cultural thing because the Pakistani culture is different from Hindi a person is supposed to utilize only their own cultural language.

\section{5) Discussion}

This study clarifies that the high amount of cable T.V viewership affects the language of youth especially the language of young Pakistani females. The study highlights that youngest females spend their 4- 6 hours watching T.V. The results signify that the youth of Pakistan is somehow fascinated by Indian dramas and Indian culture depicted in these dramas and this major exposure is affecting their language, culture and their identity. They try to somehow adopt the Hindu culture, use the Hindi language as fun without realizing the fact that this process is affecting their own language, whereas some students prefer to watch 1- 3 hours T.V on a daily basis and at that moment they like to watch Pakistani dramas more than the Indian ones.They consider that watching Indian dramas affect their socio-cultural identity, their religion, and language which is not good to be considered in Pakistani society that is why they prefer to watch Pakistani channels more than the Indian ones.

More than $45 \%$ of the population prefers to use Hindi words in their daily life with their family, friends and in their social circle whereas some restrict its usage to some specific persons. The participants consider that they have learned these words from watching Indian 
dramas. Mostly, participants consider that star plus are the main promoter of the Hindi language because they watch dramas on this channel more frequently than Zee T.V and Sony.

The result clearly indicates that the Hindi language is slowly creeping in to the language of Pakistani youth and they are mindlessly using it without any realization that this process is affecting their own language as well as the social, cultural identity of their nation. The Pakistani youth is under the influence of other cultures and the actual promoters of these cultures are the cable operators and dish antennas providers and distributers. This is an alarming sign to Pakistani media operators that due to the airing of Hindi dramas on cable and dish antenna network, Pakistani youth is getting destroyed and side by side becoming a source of promotions of Indian language and culture.

\section{Conclusion}

This study concludes that young Pakistani females frequently use the Hindi language in their daily routine with their friends, family and colleagues. They consider that the use of a different language makes them sound cool amongst their peers. The major source of learning these Indian proverbs, phrases and dialogues are the Indian dramas that are on air in T.V and cable net. Most young females frequently watch T.V for more than 4 hours; they observe a different language and culture implied it into their lives. One thing is highlighted as a positive point that some of the young females taken Hindi drama viewership as a good practice because they consider it against their culture and religion. The government needs to take positive steps regarding the spread of the Hindi language. The wide use of Hindi language in Pakistani society is a sign that Pakistanis are moving towards the time of their colonization again; as they are colonizing themselves tothe Indians. Pakistan is a country that people got many years ago for the sake of Islam and for the freedom of performing the religious duties, it is again getting into the hands of non- Muslims. PEMRA which is responsible for on-air materials on T.V in Pakistan banned Hindi channels on T.V in August 2019, but some cable operators are on-airing them in an illegal way. PEMRA needs to be aware of those cable operators and take strict action against them so that the Pakistani youth can be liberated from the clutches of Indian media war and Pakistani culture and language can get their dignity and due respect in the society and the world.

\section{References}

Ashfaq, A. (2018). Contested Images of 'Perfect Women'. Journal of the Research Society of Pakistan, 19.

Bailey, W. S. (2014). Women watch more TV than men. SAN ANTONIO BUSINESS JOURNAL.

Batool, F. (2017). Influence of foreign culture on Pakistani films. Bahria Universtiy Tribune, 4.

Bloomfield, L. (n.d.). Language. Motilal Banarsidass Publishers. 
Hassan, S. A., Khalid, A., \& Ali, A. (2015). The Impact of Indian Dramas on Language and Dressing of Females. Online Journal of Communication and Media Technologies, 15.

Hayes, J. P. (n.d.). Language and Learning in the Digital Age.

Juni, M. A. (2014). The Influence of Indian Culture on Pakistani Society: A Case Study of Layyah City. International Journal of Innovation and Applied Studies , 6.

Mahmood, M. (2018). Effect of Cable TV on Educational Performance of Distance Learners. International Journal of Distance Education and E-Learning.

Majeed, O. (2018). Are Indian dramas changing Pakistani culture? Samaa.

Schwartz. (2010). Examining the Light and Dark Sides of Emerging Adults' Identity: A Study of Identity Status Differences in Positive and Negative Psychosocial Functioning. Journal of Youth and Adolescence.

Shah , S. K., \& Aziz, H. (2017). The Effect of Hindi Animated Cartoons Causing the Language Change in Pakistani Children - A Socio-Cultural Approach of Ideology. Journal of the Punjab University Historical Society, 8.

Shrum, L. (2017). Cultivation Theory: Effects and Underlying Processes. ResearchGate, 12.

Yousaf, Z. A. (2014). Impact of Indian Dramas on Interaction behavior of female. Journal Of Humanities And Social Science.

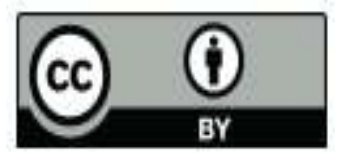

@ 2017 by the author. Licensee University of Chitral, Journal of Linguistics \& Literature, Pakistan. This article is an open access article distributed under the terms and conditions of the Creative Commons Attribution (CC BY) (http://creativecommons.org/licenses/by/4.0/). 